\title{
Cultural Differences between Learners and its Impact on the Development of Blended Learnings: an Analysis of Shift Supervisors in Austria, China, The Czech Republic, Great Britain, Indonesia and The United States
}

\author{
Doris Kogler \\ University of Applied Sciences Upper Austria, Hagenberg, Austria
}

\begin{tabular}{|l|l|}
\hline $\begin{array}{l}\text { 2019 Research Leap/Inovatus Services Ltd. } \\
\text { All rights reserved. }\end{array}$ & $\begin{array}{l}\text { The education and training of employees is an elementary component of many companies. To ensure } \\
\text { an efficient further education of employees, trainings should be optimally adapted to the respective } \\
\text { target group. Here, among other things, the culture of the learner plays a major role. This paper is } \\
\text { based on findings identified in an internationally active Austrian company. Six of the largest sites } \\
\text { of }: \text { http://dx.doi.org/10.18775/jibrm.1849- } \\
\text { 8558.2015.46.3001 } \\
\text { Republic, Great Britain, Indonesia and the United States. The goal of this survey is to reveal the } \\
\text { biggest differences regarding learning preferences and learning strategies of the company's shift } \\
\text { Sultural difference, Blended learning, Shift } \\
\text { Supervisor, Adaptation, Personal relationship } \\
\text { blended learnings. Based on the findings, recommendations for action should be made to allow for } \\
\text { adaptations of future blended learnings and to better meet the culturally diverse needs of the } \\
\text { company's shift supervisors. To reach these goals, a qualitative research with sixteen semi- } \\
\text { structured expert interviews will be carried out. The informants will be employees of the six } \\
\text { different production sites of the company and external trainers that have already worked with the } \\
\text { company. All of them are experienced in the development and/or implementation of trainings for } \\
\text { one or more of the discussed cultures. Up to the present time, fourteen interviews have been carried } \\
\text { out and transcribed. In a first step, to offer preliminary findings for this paper, four interviews with } \\
\text { the employees from the Czech Republic and the United States have been analyzed. Based on these } \\
\text { interviews it can be noted that there are a lot of similarities in learning behavior of shift supervisors } \\
\text { in the Czech Republic and the US. The discovered differences deal with the personal relationship } \\
\text { between trainer and learner, the combination of participants in face-to-face trainings and the } \\
\text { perceived self-efficacy of learners. }\end{array}$ \\
\hline
\end{tabular}

\section{Introduction}

The education and training of employees is an elementary component of many companies. Personnel development measures, however, can be very expensive. In order to ensure an efficient further education of employees, trainings must be optimally adapted to the target group. Among other things, especially the culture of the learner plays a major role. Lippold (2015) names culture as one of the most enduring factors influencing people's perceptions and behavior. The culture in which people grow up and / or live not only conveys their language, but also their attitudes, values and behavior.

In order to design successful trainings, which motivate learners, it is essential to know cultural differences and to consider them in the conception and implementation of learning measures (Altugan 2015). Particularly internationally active companies should consider the culture of their employees in the design and implementation of personnel development measures. An internationally active Austrian company recognized this problem. To better understand the cultural differences of their employees and to give recommendations for the designing of future trainings, a survey is carried out.

\section{Theoretical Framework}

This work is based on two different theoretical fields. On the one hand this paper deals with learning, learning preferences and learning strategies and on the other hand, cultures and cultural differences are discussed. To clarify various terms and models around learning and culture a literature research was conducted. The findings of this research are presented in the following chapters. 


\subsection{Learning}

Although - or probably because - learning is part of our everyday life and everyone has already learned, there is a huge variety of different ways of seeing and defining learning. Konrad (2014) therefore doesn't provide one all-encompassing definition of the term "learning", but considers the term from different points of view. These include, for example, the neurophysiological as well as the cognitivist and the socialconstructivist view. Neurobiological studies describe learning as a modification of existing codes under the influence of new codes. These so-called "codes" represent knowledge. The more often a code is used, the stronger it is and the better one can remember what he or she has learned. In contrast to the neurobiological view, which has a scientific origin, cognitivism and social constructivism are concepts from psychology. In the former - cognitivism - learners are considered as informationprocessing beings. The underlying idea of this view is that learning is the active processing of information rather than the passive acquisition of information. Representatives of the socio-constructivist view go one step further and describe learning as a self-directed process in which learners build new knowledge based on their personal experience and prior knowledge. Moreover, the socio- constructivist view of learning assumes that knowledge acquisition takes place in a particular situation and with a socio-cultural background. Thus, new knowledge stored by a person is strongly influenced by prior knowledge, experiences, and opinions (Konrad 2014). Schiefele and Heinen (2001) also describe learning from a psychological view. They define learning as the relatively permanent change of behavior or behavioral possibilities due to experience.

In the following subchapters, first of all, the term "blended learning" will be defined. Afterwards influencing factors on learning success, discovered during the literature review, will be discussed.

\subsubsection{Blended Learning}

In blended learning, electronic learning elements and traditional forms of direct learning are mixed together to one learning arrangement (Zaugg 2008). New forms of learning, such as eLearning courses, which have been made possible in recent years by digitization and networking, are combined with "classical" learning methods such as lectures (Erpenbeck, Sauter \& Sauter 2015). Blended learning thus enables the advantages of two learning arrangements - virtual and nonvirtual elements - to be optimally combined. According to Erpenbeck et al. (2015), blended learning promotes selfdirected learning as well as independent thinking and acting. In addition, the use of eLearning courses in a company can reduce the number and duration of seminar days and thus save costs. Furthermore, disadvantages of pure eLearning, such as the lack of personal contact can be avoided whereas advantages, like the efficient engagement of learners with the basic knowledge of a topic, can be optimally utilized (Zaugg 2008).

\subsubsection{Influencing Factors on Learning}

The carried-out literature review revealed five factors that can influence the learning success. These influencing factors are the methodology, the study approach, personal factors, the perceived self-efficacy and learning strategies. All mentioned factors can be seen in the following illustration Figure 1.

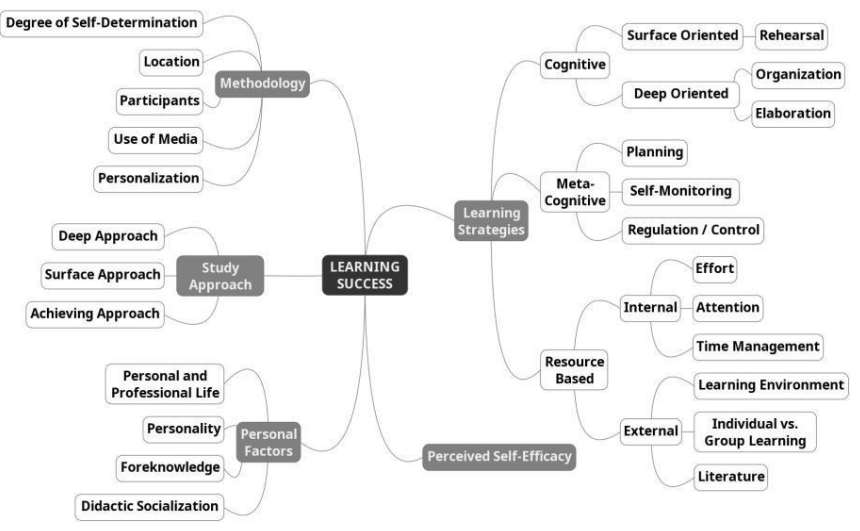

Figure 1: Influencing factors on learning success

Due to the fact that the methodology is strongly depending on the topic and most personal factors are too individual for this study, the main focus of influences will be on the study approach, the didactic socialization, the perceived self-efficacy and the learning strategies of learners in different cultures. Those factors will be discussed in more detail in the following paragraphs.

\section{Study approach}

The study approach from Biggs (1976) comprises three socalled motive-strategy combinations. These describe, on the one hand, the motive or reason why a person learns and with which motivation they approach a learning situation. On the other hand the strategy states with which approach learners want to achieve the goal. By combining three different motives (deep motives, surface motives, motivating motives) with three different strategies (deep strategy, surface strategy, achieving strategy) Biggs (1987) identified three study approaches: deep approach, surface approach and achieving approach. The deep approach describes learners which are intrinsically motivated. Learners with deep approach are interested into the topic and deal independently with the learning content. Thereby they combine new with existing knowledge. According to Biggs (1987) the second group of study approaches is the surface approach. The main goal of learners with surface approach is to achieve the minimum requirements with minimum effort. They are motivated by pragmatic reasons like the prospect of a higher earning or a promotion (Creß 2006). The last study approach from Biggs (1987) is the achieving approach. This is based on the wish of learners to compete with others and to be better than them. Learners with the achieving approach put a lot of effort into learning. Among other things, especially the organization of the learning time and environment plays an important role for these learners. 


\section{Didactic Socialization}

Socialization deals with the interplay of personal development and adaptation of a person to society. The personality of an individual is affected by its surrounding society. At the same time society is created by the different personalities in it.

Didactic socialization consists of formative experiences gathered by individuals in the context of learning. These experiences may have been made at school, at university or within the own family (Hummrich \& Kramer 2017). The sum of the learning experiences influences the individual approach and attitude of learners towards future learning situations (Haller, 1996).

\section{Perceived Self-Efficacy}

The concept of perceived self-efficacy was developed in the 1970 s by the learning process researcher Albert Bandura (Gebauer 2013). Hohmann and Schwarzer (2009) define perceived self-efficacy as the subjective certainty of being able to cope with new or difficult requirements due to one's own competence. Opinions and expectations about one's own competences have implications for goal setting, choice of strategy, and the effort and perseverance of learners. The influence on a person's thinking, feeling and acting therefore changes their access to and behavior in learning situations (OECD 2004).

\section{Learning Strategies}

Weinstein and Mayer (1983) were among the first to study learning strategies. Their definition is as follows:

"Learning strategies can be defined as behaviors and thoughts in which a learner engages and which are intended to influence the learners encoding process. Thus, the goal of any particular learning strategy may be to affect the learner's motivational or affective state-or the way in which the learner selects, acquires, organizes, or integrates new knowledge."

Learning strategies are learning behaviors a person shows in a specific situation to gain new knowledge and skills. Researchers assume that learners have a range of approaches from which they intuitively choose the most appropriate for their situation (Alonso, Blumentritt, Olderog \& Schwesig 2017). Due to the fact that learning strategies cover a wide range of approaches and strategies, research usually distinguish between three categories of strategies. Those are cognitive, meta-cognitive and resource based strategies. Cognitive strategies deal with the processes responsible for the immediate acquisition, processing and storage of information (Wild 2005). Learners can choose between three different cognitive strategies. Depending on the strategy, learners try to learn by repeating the content, reorganize information or individually engage with the learning material. Meta-cognitive strategies help learners to plan, monitor and manage their learning process. Resource based strategies finally help learners to organize their internal and external resources. While internal resources include the learner's attention, effort and time management, external resources focus for example on the learning environment and additional literature (Wild 2005).

\subsection{Culture}

Every person in the world lives at all times of his or her life in one or more cultures. Besides the classical meaning of national culture, this can also be the culture within an organization, a company or any other type of group. The culture of a society is part of the identity of humans. It gives them a feeling of belonging and sets norms about "right" and "wrong" or "beautiful" and "ugly" (Hofstede 1984; Thomas 2017).

Since culture is such a global and omnipresent subject, there is a multitude of definitions and explanations of the term "culture". The UNESCO General Conference describes culture as a set of unique characteristics that characterize a social group. These characteristics can be spiritual, material, intellectual or emotional. Moreover, in the view of the UNESCO General Conference, culture also includes value systems, traditions and ways of living (UNESCO Commission 2002). House, Hanges, Javidan, Dorfman und Gupta (2004) and Hofstede (1984) see common values, beliefs, motives and worldviews as central elements of a culture that distinguishes one group of people from another. According to Thomas (2017) culture additionally includes specific symbols such as language, gestures and facial expressions.

A culture is usually passed on through generations. Children, for example, learn their way of thinking and acting from their parents, students from their teachers and employees from their supervisor (Hofstede, 1984). In an oft-cited explanation of culture, Hofstede (2011) defines this learned mindset as "collective programming of the mind that distinguishes the members of one group or people from others".

\subsubsection{Cultural dimensions}

Cultural dimensions offer the possibility to reduce the complexity of cultures and offer interesting conclusions. Nevertheless, it is important to keep in mind that cultural dimensions easily lead to stereotyping. In the following paragraphs the cultural dimensions from Hofstede and the GLOBE study are introduced.

Hofstede's cultural dimensions are the most widespread basis for intercultural research (Van Ness et al. 2005). The dimensions of the Dutch Cultural Studies expert are largely based on a study he conducted from 1967-1972 for the international company IBM. In this study, global survey data was collected from IBM employees in 40 countries.

As a result, Hofstede discovered six cultural dimensions, which can be used to describe cultural differences. Those dimensions can be defined the following way (Hofstede 2011): 
- Power Distance: Describes how less powerful people in society perceive, accept or even expect the uneven distribution of power.

- Uncertainty Avoidance: Reflects the fear of a culture of unknown and uncontrollable situations.

- Individualism vs. Collectivism: Relate to the integration of individuals into groups.

- Masculinity vs. Femininity: Describes the division of emotional roles between woman and men.

- Long Term vs. Short Term Orientation: Reflects the choice of a culture to focus on the future or the present and past.

- Indulgence vs. Restraint: Based on the satisfaction versus control of basic human desires in the context of the enjoyment of life.

Another popular research, the GLOBE study, was carried out in a worldwide 11 -year study by 170 researchers. The focus of this cross-cultural research, which was published in 2014, was on culture and leadership. Some of the nine dimensions are very similar to Hofstede's findings. The GLOBE dimensions are defined as follows (Grove 2005):

- Power Distance: Based on the extent to which individuals accept and endorse authority, power differences and status privileges.

- Uncertainty Avoidance: Describes how much a culture relies on social norms and rules to reduce the unpredictability of future events.

- In-Group Collectivism: Degree of pride and loyalty of individuals in their culture.

- Institutional Collectivism: Based on the degree to which cultures encourage and reward collective distribution of resources and actions.

- Future Orientation: Reflects the encouragement of societies to plan and delay gratifications.

- Performance Orientation: Reflects the extent to which a community promotes and rewards innovation, excellence and performance improvement.

- Assertiveness: Describes to which extent members of the culture are assertive, confrontational and aggressive in their dealing with others.

- Gender Egalitarianism: Relate to the extent to which a culture minimizes gender inequality.

- Humane Orientation: Describes how much individuals are encouraged to act fair, friendly, generous, caring and kind to others.

\subsection{Learning and Culture}

Various researches show that culture has a crucial impact on learning. Already in the early 90s Merlin (1991) discovered that "the brains of many individuals in a particular culture are broadly programmed in a specific way, while in another culture they may develop differently". Based on the differences in their programming, learners have different ways of acquiring information (Faiola \& Macdorman 2008). For this reason, different cultures might require different activities and strategies to motivate learners (Altugan 2015).

In 2009, Uzuner (2009) collected multiple studies which deal with cultural differences in learning. Through his analysis the author discovered, amongst other things, following coherences between learning and the cultural dimensions explained above:

- Learners from high uncertainty avoidance cultures are threatened by unstructured and unclear learning situations.

- Learners from collectivist cultures appreciate to build relationships while their learning process.

- Learners from large power distance cultures are intimidated by the idea of approaching their instructors.

- Learners from Asian countries, where they have a high power distance and see teachers as authority figures, value teacher feedback more than peer feedback and like to see the teacher in person.

\section{Research Objectives}

The main objectives of this research are to discover cultural differences in learning strategies and learning preferences between shift supervisors in the sites of an internationally operating company in Austria, China, the Czech Republic, Great Britain, Indonesia and the United States. Furthermore, it should give recommendations on how to develop and implement blended learnings to fit the cultural needs of shift leaders in each country.

Following questions should be answered as a result of this research:

- What intercultural challenges does the conception and implementation of behavior- changing blended learnings bring for shift supervisors in Austria, China, the Czech Republic, Great Britain, Indonesia and the USA?

- What intercultural recommendations for action can be made for the conception and implementation of behaviorchanging blended learnings for shift supervisors in Austria, China, the Czech Republic, Great Britain, Indonesia and the USA?

Due to the fact, that this study is still ongoing, the preliminary findings presented in this paper will only focus on the following question:

(1) What intercultural challenges does the conception and implementation of behavior- changing blended learnings bring for shift supervisors in the Czech Republic and the USA?

\section{Research Methodology}

As an empirical method expert interviews will be carried out. The experts will be interviewed using a partially standardized interview guide. The method of expert interviews was chosen 
in order to be able to raise the practical experience and knowledge of people who already faced the challenge of organizing trainings for one or more of the chosen countries. The sample selection of the interviewees was carried out in cooperation with the contracting company. In addition to employees of the company, external training partners will participate in the survey. In total, sixteen interviews will be carried out between February and April 2018

\subsection{Limitations}

Like in every empirical study, this research includes limitations based on the methodology. First of all, the interviewer effect, which states that the interviewer subconsciously influences the interviewee's answers, should be considered. Furthermore, the personal attitude and worldview of the author influences the results. Although it was tried to objectively conduct and interpret the interviews, the possibility of subjective conclusions and interpretations cannot be entirely excluded.

Moreover, it is important to note that the findings of this study are based on the knowledge of learning experts about the behavior and preferences of shift supervisors in the contracting company. Therefore, beside the national culture, the unique culture of the company plays a role in the conducted findings. Finally, it should be indicated that this survey is based on the statements of a small group of experts. The limited number of two experts per production site means that the findings can be of a very subjective nature.

Nevertheless, the findings of this study should not be considered as generally valid rules but as rough guidelines in the development and implementation of blended learnings primarily in the Czech Republic and US. According to the results of this study and previous researches around the world, those can serve as an indicator that there will be probably found cultural differences toward the presented topic also in relation to Great Britain, Indonesia, Austria, China and Great Britain or similar.

\section{Preliminary Findings}

Up to the present time, fourteen interviews have been carried out and transcribed. Detailed information about the conducted interviews and the interview partners can be seen in the following Table 1.

Up to the current date the interviews of - in total - four employees from the company's production sites in the Czech Republic and the United States have been analyzed. Therefore, this chapter will mainly focus on the learning behavior and preferences of shift supervisors in the Czech Republic and the US.
Table 1: Overview of the conducted interview data

\begin{tabular}{llc}
\hline \multirow{2}{*}{ Gender } & Male & 7 \\
& Female & 7 \\
\hline \multirow{3}{*}{ Duration of the interviews } & Minimum & 20 minutes \\
& Maximum & 75 minutes \\
& $\varnothing$ & 50,2 minutes \\
\hline \multirow{5}{*}{ Participants } & HR Austria & 2 \\
& HR China & 2 \\
& HR Czech Republic & 2 \\
& HR Great Britain & 1 \\
& SHE Great Britain & 1 \\
& HR Indonesia & 1 \\
& CIP United States & 1 \\
& HR United States & 1 \\
& External trainer & 3 \\
\hline Total Participants & \\
\hline CIP = Continual Improvement Process, SHE = Safety, Health \& Environment
\end{tabular}

Based on the detected findings, it can be stated that shift supervisors in the Czech Republic and the US have similarities as well as differences in their preferred learning behavior. In the following chapter, first of all the similarities of the cultures are discussed before the preliminary found differences between shift supervisors in the Czech Republic and the US will be presented. Due to the interviewees, following general valid statements about learning and shift supervisors can be made:

\section{General}

- Learning behavior, learning preferences and the motivation for learning can be very individual and differ from person to person.

- Shift supervisors need a strong reason why they should participate in a training. Therefore, it is important to explain the purpose and the goal of a training.

- The content of a training is elementary for shift supervisors. They want to learn practical things they can use in their dayto-day work life.

- Shift supervisors learn to be successful in their job and leading their shift. Furthermore, some shift supervisors are personally interested into the offered topics.

\section{Blended Learning}

- Blended Learnings can be started with a face-to-face training or an eLearning. While starting with face-to-face training offers the possibility to explain the training and build personal relationships, starting with an eLearning allows learners to have a look into the topic before meeting face-to-face.

\section{Participant in face-to-face trainings}

- The combination of participants is restricted by the shifts. The company's production runs 24 hours a day. That's why some of the shift supervisors always have to work. Due to the fact that there are only nine shift supervisors in the Czech Republic and eight shift supervisors in the US, the combination of participants for trainings are limited. 


\section{eLearning}

- Shift supervisors in the Czech Republic and the US aren't used to eLearning. There have hardly been any virtual learning elements in this production sites until yet.

- Offering eLearning on mobile devices is seen as a good possibility for younger employees to access eLearning.

- It is better to offer multiple short (maximum 30 minutes) eLearning modules than one big one.

Beside the similarities in the learning behavior of shift supervisors in the Czech Republic and the US, the conducted interviews revealed some differences. The three biggest differences in attitudes to and behavior in learning situations will be discussed in detail in the following paragraphs.

\subsection{Personal Relationship}

The interviewees were asked if they think that the personal relationship between trainer and learner is important for shift supervisor and if this relationship helps shift supervisors to learn. In the US the personal relationship is seen to be preferable but not necessary as the following vignette demonstrates:

"I mean I think it is helpful... but... you know... can they still learn without a personal relationship? Probably though." (Interview 03)

In the Czech Republic on the other hand, the personal relationship between trainer and learner is perceived as an important part of trainings. Due to the interviewees, a recent intern survey showed that employees in the Czech Republic prefer having a real trainer, who they can trust, talk to and ask questions. The following statements confirm these findings:

"They need to trust the person who teach them. They need to believe." (Interview 04)

"We asked them ... did a little survey if maybe that would be an issue for them, if only they had eLearning, for example language courses in eLearning and definitely no! So definitely... they want to have a lecturer or a teacher or a trainer to confront or talk with." (Interview 05, translated from German)

To match the preliminary findings of this survey with cultural characteristic of a nation, the dimensions of Hofstede will be used. Unfortunately, the Czech Republic wasn't considered in the GLOBE study and therefore do not offer values for the country.

The findings regarding the personal relationship between trainer and learner could be based on the cultural differences in Hofstede's individualism vs. collectivism and uncertainty avoidance. The US shows a higher individualism and lower uncertainty avoidance then the Czech Republic.

\subsection{Perceived Self-Efficacy}

While shift supervisors in the US seem to be quite selfconfident before participating in trainings, the nervousness of shift supervisors in the Czech Republic depends on the personality of the learner and the topic. Especially soft skills trainings, in which learners have to do a presentation, make shift supervisors feel uncomfortable. This finding is based on statements from experts of the Czech Republican Human Resources Department like:

"Maybe they will be a little bit more nervous because they know that they will have to show something there." (Interview 04)

"Not everyone is used to being in front of people, even if they are colleagues, to make a presentation. And then they are uncertain for example." (Interview 05, translated from German)

Comparing the light insecurity of shift supervisors in the Czech Republic regarding soft skill trainings to the cultural dimensions of Hofstede leads to the assumption that the higher uncertainty avoidance of the Czech Republic influences their perceived self-efficacy.

\subsection{Participants of Face-to-Face Trainings}

Although the combination of shift supervisors in face-to-face trainings is strongly predetermined by the shift schedule of the shift supervisors in the Czech Republic as well as in the US, the interviews revealed some differences. While experts of both cultures recommend on mixing participants based on their gender, age and personality, the hierarchy seems to play an important role for shift supervisors in the Czech Republic and no role in the US. This can be underlined by following vignettes from experts in the US:

"No... not really. I mean usually you are restricted by the schedule anyway so - no. I think they would be fine no matter what the structure of the group was." (Interview 01)

"I don't think there are any restrictions regarding the age or hierarchy of the participants. I mean I think because of its... an age or some people have been more... shift supervisor for longer than another one. That's only helpful - to have a mixture of experiences." (Interview 03)

In comparison to the US, Czech Republican experts do not recommend to put shift supervisors in one training group with their boss. In exchange, the mixing of different types of personalities seems to be very important in the Czech Republic as the following quotes show:

"My experience is I always tried to invite the most active and the less active I knew I have in the team or in the group. Not less active, but maybe the most critical person. [...] It depends on the topic. But in case of... let's say soft skills I would 
recommend not to put the manager [into one group with the employee]." (Interview 04)

"So ideally I would choose the group so that there really is such a mixture that ... introverted and extroverted ... I would mix that up a bit. [...] So, I would not care that I have only the young people or just the older generation together. The two can benefit from each other ... and if the coach is skilled, then he can work very well with it. [...] I certainly would not put employees with their direct superior in one course." (Interview 05 , translated from German)

Based on the dimensions of Hofstede, the differences in the judgement of hierarchy in trainings can be explained by the higher power distance of the Czech Republic compared to the slightly lower power distance of the US.

\section{Conclusion}

Overall, it can be summarized that shift supervisors in the Czech Republic and the US show a lot of similar attitudes, behaviors and preferences towards learning. This is presumable due to the fact that culture is just one influencing factor on learning. The human nature and the personality of a person are two further crucial factors which can and should not be ignored. Besides the similarities, some differences between shift supervisors in the Czech Republic and the US could be revealed in a first step. First of all, the importance of the personal relationship between trainer and learner is perceived differently. While the relationship is elementary for shift supervisors in the Czech Republic and they want to be able to trust their trainer and to see and ask him / her questions in person, experts from the US think that a relationship is preferable but not necessary. Secondly, shift supervisors from the Czech Republic tend to be nervous about soft skills trainings whereas shift supervisors from the US seem to be confident in all kind of trainings. Additionally, differences between the recommended combinations of participants in a face-to-face training could be discovered. Although experts from the Czech Republic as well as their colleagues from the US think that mixing different genders, age groups and personalities is a good idea, they have different opinions about putting multiple layers of hierarchies in one course. Due to the interviewees, shift supervisors in the US do not care so much about the hierarchies and can be put in trainings with their direct superior without any problems. Shift supervisors from the Czech Republic, on the other hand, don't want to participate in a course, especially a soft skills training, with their superior.

\section{References:}

- Alonso, Gardenia, Blumentritt, Marianne, Olderog, Torsten \& Schwesig, Roland (2017), Strategien für den Lernerfolg berufstätiger Studierender: Empirische Analysen zum Lernverhalten. Wiesbaden: Springer. Crossref
- Altugan, Arzu S. (2015), "The Relationship between Cultural Identity and Learning" in Procedia - Social and Behavioral Sciences, Vol. 186, 1159-1162. Crossref

- Biggs, John B. (1987), Student Approches to Learning and Studying. Camberwell, Australien: Australian Council for Educational Research.

- Creß, Ulrike (2006). "Lernorientierungen, Lernstile, Lerntypen und kognitive Stile“ in Handbuch Lernstrategie, H. Mandl \& H. F. Friedrich, eds. Göttingen: Hogrefe, 365377.

- Erpenbeck, John, Sauter, Simon \& Sauter, Werner (2015), E-Learning und Blended Learning: Selbstgesteuerte Lernprozesse zum Wissensaufbau und zur Qualifizierung. Wiesbaden: Springer. Crossref

- Faiola, Anthony \& Macdorman, Karl F. (2008), "The Influence of Holistic and Analytic Cognitive Styles on Online Information Design: Toward a Communication Theory of Cultural Cognitive Design" in Information, Communication \& Society, Vol. 11, 348-374. Crossref

- Gebauer, Miriam M. (2013), Determinanten der Selbstwirksamkeitsüberzeugung von Lehrenden: Schulischer Berufsalltag an Gymnasien und Hauptschulen. Wiesbaden: Springer. $\underline{\text { Crossref }}$

- Grove, C. (2005). Worldwide Differences in Business Values and Practices: Overview of GLOBE Research Findings. Grovewell: Global Leadership Solutions Web site. https://www.grovewell.com/wp-content/uploads/pubGLOBE-dimensions.pdf. Accessed March 19, 2018.

- Hofstede, Geert (1984), "Cultural Dimensions In Management And Planning" in Asia Pacific Journal of Management, Vol. 1, 81-99. Crossref

- Hofstede, Geert (2011), "Dimensionalizing Cultures: The Hofstede Model in Context" in Online Readings in Psychology and Culture, Vol. 2. Crossref

- Hohmann, Cynthia \& Schwarzer, Ralf (2009), "Selbstwirksamkeitserwartung", in Handbuch der Gesundheitspsychologie und Medizinischen Psychologie, Jürgen Bengel and Matthias Jerusalem, eds. Göttingen: Hogrefe, 61-67.

- Hummrich, Merle \& Kramer, Rolf-Torsten (2017), Basiswissen Sozialisation. Wiesbaden: Springer. Konrad, Klaus (2014), Lernen lernen - allein und mit anderen: Konzepte, Lösungen, Beispiele.

- Lippold, Dirk (2015), Die Marketing-Gleichung: Einführung in das prozess- und wertorientierte Marketingmanagement. Berlin: DeGruyter. $\underline{\text { Crossref }}$

- Merlin, Donald (1991), Origins of the Modern Mind: Three Stages in the Evolution of Culture and Cognition. Cambridge: Harvard University Press.

- OECD (2004), Lernen für die Welt von morgen: Erste Ergebnisse von PISA 2003. Paris: OECD. Schiefele, Ulrich \& Heinen, Stefanie (2001), "Wissenserwerb und Motivation“, in Handwörterbuch 
- Pädagogische Psychologie, Detlef H. Rost, eds. Weinheim: Beltz, 795-799.

- Thomas, Alexander (2017), Technik und Kultur: Interkulturelle Handlungskompetenz für Techniker und Ingenieure. Wiesbaden: Springer. $\underline{\text { Crossref }}$

- UNESCO Commission (2002), “Allgemeine Erklärung zur kulturellen Vielfalt. German Commission for UNESCO Web site. http://www.unesco.de/infothek/dokumente/unescoerklaerungen/erklaerung- vielfalt.html. Accessed October 13, 2017.

- Uzuner, Sedef (2009),"Questions of Culture in Distance Learning: A Research Review" in International Review of Research in Open and Distance Learning, Vol. 10. Crossref

- Van Ness, R. K., Seifert, C., Franko, G. \& Buff, C. (2005), "Hofstede's cultural dimensions: Are individual differences important?" in International Journal of Business Research, Vol. 2, 161-166.

- Weinstein, Claire E. \& Mayer, Richard E. (1983), "The teaching of learning strategies" in Innovation Abstracts, Vol. 5.

- Wild, Klaus-Peter (2005), "Individuelle Lernstrategien von Studierenden. Konsequenzen für die Hochschuldidaktik“ in Beiträge zur Lehrerinnen- und Lehrerbildung, Vol. 23, 191206.

- Zaugg, Robert J. (2008), "Nachhaltige Personalentwicklung", in Moderne Personalentwicklung: Mitarbeiterpotenziale erkennen, entwickeln und fördern, Norbert Thom and Robert J. Zaugg, eds. Wiesbaden: Gabler, 19-40. $\underline{\text { Crossref }}$ 